\title{
Level of Knowledge and Attitude of the Patients Older than 65 Years About Pneumococcal Vaccine
}

\author{
Umut Gök Balc1 $^{1}$, Dr. Yasemin Şimşek ${ }^{1}$, Nazlı Soysal ${ }^{1}$ and Kurtuluş Öngel ${ }^{1,2}$ \\ 1. Department of Family Medicine, İzmir Tepecik Education and Research Hospital, Izmir 35110, Turkey \\ 2. Department of Family Medicine, Faculty of Medicine, İzmir Katip Çelebi University, İzmir 35620, Turkey
}

Received: February 2, 2015 / Accepted: March 31, 2015 / Published: March 31, 2015.

\begin{abstract}
Pneumococcal vaccine is a high protectional vaccine that is especially recommended for patients with COPD (chronic obstructive pulmonary disease) over 65 years. It is important for the prevention of many complications secondary to infection. In present study, it is aimed to determine the level of knowledge and attitude of the patients over 65 years, who had admitted to hospital for any reason, about pneumococcal vaccine. Study was performed on December 2013. Thirty-three patients over 65 years, who were admitted to İzmir Tepecik Education and Research Hospital for any reason, were chosen randomly. A questionnaire, related with this aim, was performed. Date were evaluated as percentages. Fifteen patients were men (45.6\%) and 18 were women (54.4\%). Forty-two percent were housewife (n:14), 18.4\% (n:6) were retired, others were from different professions. Only 1 patient had an university degree and 14.8\% (n:5) were illiterate. Number of the patients who heard about pneumonia was 18 (54.6\%). Among them, 94\% (n:17) described pneumonia correctly. Only 1 patient had pneumonia, hospitalized and treated in the past. All of the patients stated that they don't have lower respiratory tract infection and influenza infection so often. Sixty-three point five percent (n:21) of the patients has heard about pneumococcal vaccine. Of the $21,54.5 \%$ had heard from their family doctor, $46.5 \%$ from social media. None of the patients have an idea about the protective effects of the vaccine. Only 18.4\% (n:6) of the patients had pneumococ vaccine, and only $12.3 \%$ of them mentioned about its benefits. The percentage of patients who have correct knowledge about vaccination period was $21.7 \%$ (n:7). The percentage of patients who know the side effects of the vaccine was around $33.2 \%$ (n:11). Knowledge level of the patients over 65 years about pneumococ vaccination was quite low and only small part of the patients were vaccinated. Family doctors must play an important role on this subject.
\end{abstract}

Key words: Infection, pneumococ, vaccine.

\section{Introduction}

Streptococcus pneumoniae is a gram-positive, alpha-hemolytic, anaerobic microbe. It is aero tolerant, spore-free, immobile and capsulated member of the genus Streptococcus. It is an important risk factor for the community, especially for the elderly.

Advanced age is a special issue that requires a different approach in psychological, physiological and socioeconomic aspects. Nowadays the healthy and independent population over age 70 has increased. Recent studies prove that people who don't have a chronic disease and have a healthy lifestyle can have as

Corresponding author: Kurtuluş Öngel, Dr., professor, research fields: palliative care, epidemiology and primary care. E-mail: kurtulusongel@gmail.com. much the same body function capacities as normal. To live a healthy and functional lifestyle when growing older is multifactorial. One of them is the primary care health opportunities. Besides, vaccination is part of the primary care health services [1]. Vaccination programs for grownups especially elders are mostly ignored. Many adults are not vaccines sufficient as the vaccination programs require. Responsible for that are multifactorial like poor knowledge about vaccine preventable diseases, the discussions about efficiency and reliability of the vaccines, ignoring the age importance in vaccinating, the high vaccine prices and the poor infrastructure regarding adult vaccines [2]. The mortal cases in the age group over 65 are caused in the first place by infections (one third of all causes), in 
the second place by acute and chronic diseases [3]. The physiological changes with age and the present chronical diseases cause a different clinical course by infections [4, 5].

Pneumococcal infections cause serious complications on seniors. Community acquired pneumonie, invasive infections, meningitis are often seen by the people over 65 years. Lower respiratory tract infections caused by pneumoccal microorganism which are seen in the population by a rate of $4.4 \%$, have a third fold rate by people over age 65 [6]. The benefits of the pneumococcal vaccine/primary care over pneumococcal infections which are the most important morbidity and mortality cause by elderly population, are proven in many studies [7-10]. USPSTF (United States Preventive Services Task Force) recommend all people over age 65 without immunodefiency the pneumococcal vaccine [2].

In present study, the profit of the vaccination program, an important part of primary care, by determining the standart knowledge of random elder people over age 65 who had different hospital applications about the pneumococcal vaccine and their approach to the vaccine was assessed.

\section{Materials and Methods}

In December 2013, a survey about the pneumoccoc vaccine was implemented random on 33 people over age 65 who had come to İzmir Tepecik Education
Research Hospital with different health problems. Volunteering was the basic criteria. Subjects were asked about peumonia and pneumococ vaccine in addition to demographic values such as age, sex and so on. All data were entered into SPSS 16.0 program and percentage method was used for statistical analysis.

\section{Findings}

Study was contained 15 male (45.6\%) and 18 female (54.4\%) participants. Forty-two point two percent were housewives, $18.7 \%$ were pensioners, the others were from different work professions. Only one was university graduate and $14.7 \%$ were analphabetic. Fifty-four point six percent had heard about a disease named "pneumonia" and $93.8 \%$ of them knew the right definition. Of all patients only one had a pneumococcal infection and inpatient treatment. The study group stated that they hardly had lower inspiratory tract infections or flu. Sixty-three point five percent of them heard of pneumoccocal vaccine, $36.5 \%$ never heard of it. Fifty-four point five percent of those who have heard were informed by their family physician, $46.5 \%$ heard of it from media or their social environment. None of them had known about the vaccines protectiveness feature. Only $18.4 \%$ were vaccinated and $12.3 \%$ of them expressed seeing benefits. Twenty-one point seven percent knew about the right vaccine interval. Thirty-three point two percent knew about the vaccine side effects.

Table 1 Percentage of the answers given to the questions.

\begin{tabular}{ll}
\hline Question & Answer (\%) \\
\hline Percent of people who heard about pneumonia & 54.6 \\
Among those who heard knowing the right definition & 93.8 \\
Percent of people who had peumococcal infection & 3 \\
Rate of people who had often the flu. & - \\
Percent of people who knew about the pneumococ vaccine & 63.5 \\
Percent of people informed by the family physician & 54.5 \\
Percent of people informed by the social environment & 46.5 \\
Percent of people informed about the pneumococ vaccine protectiveness & - \\
Vaccined with the pneumococ vaccine & 18.4 \\
Benefiting from the vaccine & 12.3 \\
Being informed about the vaccine interval & 21.7 \\
Being informed about the vaccine side effects & 33.2 \\
\hline
\end{tabular}




\section{Discussion}

One of the successes of the 20th century is the decrement of diseases incident through vaccination. Protectivenes against diseases morbidity and mortality through vaccination is more important for adults than children. It is estimated that each year 30,000-50,000 adults die of diseases which could be provided by vaccination. Although there are not clear information about vaccination against pneumoccocal microorganisms, a study accomplished by Taşbakan and colleagues proved that $9.2 \%$ of COPD (chronic obstructive pulmonary disease) patients knew about the pneumococcal vaccination necessity [11].

Compared with the world literature, knowledge about the pneumococ vaccine and the vaccination rate, is rather low. In present study, the results showed that the standart of knowledge and vaccination rate for the pneumococ vaccine was similarly low. Those who knew about the pneumococ vacccine or were inoculated with the pneumococ vaccine were mostly informed and redirected by their family physician.

By a study in China's urban areas with 3,000 people over the age 60 , it was showed that $61.65 \%$ thought of pneumonia as a serious disease. Less than $50 \%$ knew about the pneumococcal vaccines efficiency and reliability and only $1.23 \%$ were immunized with the vaccine. The study signified that only steady education would increase the vaccination rate [12].

In America it is thought as only $15 \%$ of all population over 65 were in the risk group for pneumonia and that most of them should be informed of pneumonia and vaccination [13]. For this purpose special education programms are available. Streptococcus pneumonia is an important morbidity and mortality cause for elderly people all over the world. Although there are excellent antimicrobial treatment and efficient healthcare, the respiratory tract infections and invasive infections caused by pneumococs are still an important health problem. PPSV23 a 23 valent pneumococcal polysaccharide vaccine available since 1983 is recommended to seniors and for everyone who has an increased risk of infection like a chronic hearth disease, a chronic lung disease, HIV infection, sickle cell anemi, splenectomy. The serotype 23 provides protection against all invasive pneumococcal infections up to $90 \%$ worldwide. Various countries include the PPA in their national vaccine program and encourage the use of it [14]. However the sufficient education and vacination worldwide have not been provided yet.

\section{Results}

The rate for the standart of knowledge and vaccination with the pneumococ vaccine which is admitted as necessary and effective for people over age 65 is quite low. Having a more organized and efficient system for giving instructions and informations in primary care and paying more attention to the primary service should be aspired in this case.

\section{References}

[1] US Preventive Task Force. 1996. "Adult Immunizations-Including Chemoprophylaxis Against Influenza A." In Guide to Clinical Preventive Services. 2nd ed. Baltimore: Williams and Wilkins.

[2] Zeybek, Y., Tokalak, İ., and Boyacioğlu, S. 2004. "Altmışbeş yaş Üzeri Erişkinlerde Aşılanma Durumu". Türk Geriatri Dergisi 7 (3): 152-4.

[3] Mouton, C. P., Bazaldua, O. V., Pierce, B., and Espino, D. V. 2001. "Common Infections in Older Adults." Am. Fam Physician 63: 257-68.

[4] Wunderlich, C. A. 1871. On the Temperature in Diseases: A Manual of Medical Thermometry. edited by Seguin, E. New York: William Woodand Co.

[5] Shapiro, E. D., Berg, A. T., Austrian, R., Schroeder, D., Parcells, V., and Margolis, A. et al. 1991. "The Protective Efficacy of Polyvalent Pneumococcal Polysaccharide Vaccine." N. Engl J. Med. 325: 1453-60.

[6] Yoshikawa, T. T. 1997. "Perspective: Aging and Infectious Diseases: Past, Present, and Future." J. Infect. Dis. 176: 1053-7.

[7] Moberley, S. A., Holden, J., Tatham, D. P., and Andrews, R. M. 2008. "Vaccines for Preventing Pneumococcal Infection in Adults." Cochrane Database Syst. Rev. CD000422. 
[8] Jackson, L. A., and Janoff, E. N. 2008. "Pneumococcal Vaccination of Elderly Adults: New Paradigms for Protection." Clin. Infect Dis. 47: 1328.

[9] Ortqvist, A., Hedlund, J., Burman, L. A., Elbel, E., Höfer, M., and Leinonen, M. et al. 1998. "Randomised Trial of 23-Valent Pneumococcal Capsular Polysaccharide Vaccine in Prevention of Pneumonia in Middle-Aged and Elderly People.” Lancet 351: 339-40.

[10] Kartal, E. 2008. "Pneumococcal Vaccine in Adults" Turkiye Klinikleri J. Inf. Dis-Special Topics 1 (1): 18-24.

[11] Taşbakan, M. S., and Pullukçu, H. 2007. "Kronik Obstrüktif Akciğer Hastalığı Olgularında Influenza Aşılanma Oranları ve bilgi Düzeylerinin
Değerlendirilmesi." Infeksiyon Dergisi 21 (2): 89-92.

[12] Lancelot, W. H. M., Alvin, Y. S. C., Albert, L., and John, L. 2013. "Cross Sectional Study on Attitudes Among General Practitioners Towards Pneumococcal Vaccination for Middle-Aged and Elderly Population in Hong Kong." Plosone 8: 11.

[13] National Foundation for Infectious Diseases. Accessed August 10, 2014. https://www.aahivm.org/Upload Module/upload/Provider\%20Resources/Pneumococcal\%2 0CTA\%20HCP\%20Roles\%20AAHIVM\%20Partner.pdf.

[14] Öztürk, G. Z., and Toprak, D. 2013. "Vaccine Induced Adverse Reaction: Case Report." Smyrna Tip. Dergisi 3 (ek-1): 20-3. 